Article

\title{
Differentiating Authentic Adenophorae Radix from Its Adulterants in Commercially-Processed Samples Using Multiplexed ITS Sequence-Based SCAR Markers
}

\author{
Byeong Cheol Moon ${ }^{1} * \mathbb{D}$, Wook Jin Kim ${ }^{1}$, Kyeong Suk Han ${ }^{1}$, Sungyu Yang ${ }^{1}$, \\ Youngmin Kang ${ }^{1}$, Inkyu Park ${ }^{1}$ and Renzhe Piao ${ }^{2}$ \\ 1 K-herb Research Center, Korea Institute of Oriental Medicine, Daejeon 34054, Korea; \\ ukgene@kiom.re.kr (W.J.K.); hks86@kiom.re.kr (K.S.H.); sgyang81@kiom.re.kr (S.Y.); \\ ymkang@kiom.re.kr (Y.K.); pik6885@kiom.re.kr (I.P.) \\ 2 Department of Agronomy, Yanbian University Agriculture College, Yanji 133002, China; rzpiao@ybu.edu.cn \\ * Correspondence: bcmoon@kiom.re.kr; Tel.: +82-428-689-530
}

Academic Editor: Chih-Ching Huang

Received: 10 April 2017; Accepted: 20 June 2017; Published: 27 June 2017

\begin{abstract}
Determining the precise botanical origin of a traditional herbal medicine is important for basic quality control. In both the Chinese and Korean herbal pharmacopoeia, authentic Adenophorae Radix is defined as the roots of Adenophora stricta and Adenophora triphylla. However, the roots of Codonopsis lanceolata, Codonopsis pilosula, and Glehnia littoralis are frequently distributed as Adenophorae Radix in Korean herbal markets. Unfortunately, correctly identifying dried roots is difficult using conventional methods because the roots of those species are morphologically similar. Therefore, we developed DNA-based markers for the identification of authentic Adenophorae Radix and its common adulterants in commercially-processed samples. To develop a reliable method to discriminate between Adenophorae Radix and its adulterants, we sequenced the nuclear ribosomal DNA internal transcribed spacers (nrDNA-ITS) and designed sequence-characterized amplified region (SCAR) primers specific to the authentic and adulterant species. Using these primers, we developed SCAR markers for each species and established a multiplex-PCR method that can authenticate the four herbal medicines in a single PCR reaction. Furthermore, we confirmed that commercially-processed herbal medicines, which often have degraded DNA, could be assessed with our method. Therefore, our method is a reliable genetic tool to protect against adulteration and to standardize the quality of Adenophorae Radix.
\end{abstract}

Keywords: Adenophorae Radix; internal transcribed spacer (ITS); sequence characterized amplification region (SCAR) marker; multiplex PCR; molecular identification

\section{Introduction}

A common problem in herbal medicines is the adulteration and contamination by related and/or allied species, as well as those from unrelated genera [1]. It is difficult to identify authentic plant materials from adulterants and substitutes because of their morphological similarity, and confusion arises from the vernacular names of herbal medicines between provinces and countries [1-3]. Adenophorae Radix (Sa-Sam in Korean and Nan-Sha-Shen in Chinese) is an important herbal medicine that is prescribed as an antitussive and expectorant and has a wide range of immune-altering effects [4]. Adenophorae Radix is a representative herbal medicine that has been adulterated by both closely-related plant species and unrelated genera in both Korea and China [3-5]. In China, the roots of many Adenophora species belong to the Campanulaceae and related plants have been added to 
Adenophorae Radix, including Adenophora polyantha Nakai and Adenophora hunanensis Nannf. (defined as a synonym of Adenophora petiolata subsp. hunanensis [Nannf.] by D. Y. Hong and S. Ge), although it is defined as the roots of only Adenophora stricta Miq. and Adenophora tetraphylla (Thunb.) Fisch. (defined as a synonym of Adenophora triphylla [Thun. A. DC.]) [6]. The morphological characteristics of dried roots of these inauthentic species are similar to those of authentic A. stricata and A. tetraphylla $[4,7]$. In addition, the roots of Glehnia littoralis F. Schmidt ex Miq. belong to the Apiaceae, described as Glehniae Radix in the Chinese pharmacopoeia, are also used as Adenophorae Radix because of a similar medicinal name (Bei-sha-shen) in China [3,7]. Even though Adenophorae Radix is described as the roots of $A$. stricta and A. triphylla var. japonica (Regel.) Hara in the Korean herbal pharmacopoeia, the roots of diverse Adenophora species and those of Codonopsis lanceolata (Siebold and Zucc.) Benth. And Hook. f. ex Trautv. (Campanulaceae) and Codonopsis Lanceolatae Radix have also been used as Adenophorae Radix in Korean herbal markets because of the morphological similarity of the species in the same genus and the incorrect or imprecise definition of the botanical origin in ancient medical literature (http://boncho.kiom.re.kr/herbarium/codex.php) [8,9]. Furthermore, because of the similar morphological features of processed herbal medicines, the roots of Codonopsis pilosula (Franch.) Nannf. (Campanulaceae), which is defined as Codonopsis Pilosulae Radix, may also be distributed as Adenophorae Radix in Korea [9].

In traditional medicine, Adenophorae Radix, Glehniae Radix, and Codonopsis Lanceolatae Radix have different medical properties and efficacies. In detail, Adenophorae Radix has been used to nourish the yin of the lung and stomach and generate clear heat and fluids, whereas Codonopsis Pilosulae Radix has been used to tonify the middle burner (digestive system) and to augment the spleen and lung qi. Glehniae Radix also has been used to nourish the yin and generate fluids, but has been characterized for clearing the lungs and augmenting the stomach. By contrast, Cdonopsis Lanceolatae Radix has been traditionally used to detoxify and expel pus and promote milk secretion [10]. As such, the pharmaceutical prescriptions for authentic herbal medicines require quality control of herbal medicines [1]. In previous studies, identifying the botanical origins and quality of the medicines was carried out through morphological and genetic approaches, as well as chemical analysis $[3-5,9,11]$. However, these approaches have limited utility for authenticating commercially-processed Adenophorae Radix in Korean herbal markets due to degradation of DNA and the removal of morphologic features during processing. Therefore, we developed additional simple and reliable molecular genetic tools for detecting the adulterants and contaminants of Adenophorae Radix.

DNA barcoding is a reliable genetic tool used to identify species and is frequently employed to study phylogenetic relationships [12-14]. This method also has been used to identify the botanical origins of herbal medicines and for discriminating between authentic product and inauthentic adulterants $[13,15,16]$. Over 17 DNA barcode regions can be used to identify the species of Plantae and to differentiate authentic herbal medicines [1], with the genes RuBisCO $(r b c \mathrm{~L})$ and maturase-K (matK) in the chloroplast genome being commonly used [17,18]. The internal transcribed spacer (ITS) sequences within the nuclear ribosomal RNA genes (nrDNA) may be used to distinguish plants at the species level [19]. However, the nrDNA-ITS regions have been of limited use because the available primers for these sequences amplify DNA from fungi, other endophytic microorganisms, and multiple copies of the ITS regions. Recently, ITS2 has been proposed as a universal DNA barcode for identifying plant species, herbal medicines, and herbaceous dietary supplements, but it has some disadvantages, such as the complexity of the experiment, the difficulty of interpreting the results, the limitation of sample numbers, and the detection of contaminants [16,20,21]. A sequence-characterized amplified region (SCAR) marker assay can reliably and reproducibly distinguish species based on sequence information obtained from DNA fingerprinting or barcoding in diverse plants and herbal medicines. This method amplifies only target-containing samples using specific primers and differentiates positive or negative amplification of target regions, as well as length polymorphisms of target regions by gel electrophoresis of closely related samples [22-24]. Therefore, the SCAR method is simple to carry out, its results are simple to interpret, and it produces fewer errors in PCR amplification and 
sequencing [21]. Furthermore, the efficiency and ability of this assay improved with the combination of individual SCAR markers and multiplex PCR, namely, multiplexed SCAR marker assays [22,25,26]. These have been abundantly and successfully applied to authenticate medicinal plant species and commercially-processed herbal medicines [22].

A genetic assay has already been developed to discriminate between authentic Adenophorae Radix species based on $28 \mathrm{~S}$ and $5 \mathrm{~S}$ rDNA intergenic spacer region sequences of $A$. stricta, A. triphylla, A. hunanensis, and G. littoralis [4]. Another molecular genetic tool can identify authentic Glehniae Radix from common herbal adulterants, including A. triphylla and A. stricta, using ITS2 DNA barcoding [3]. However, there are differences in the range of plant species that adulterate Adenophorae Radix between Korea and China. Therefore, an additional marker is needed to authenticate Adenophorae Radix and to simplify analysis. In this study, we analyzed the entire ITS sequence of six medicinal plant species, A. stricta, A. triphylla, A. triphylla var. japonica, C. lanceolata, C. pilosula, and G. littoralis, and developed SCAR markers to differentiate the four herbal medicines using the ITS1 region. In addition, we established a multiplexed SCAR assay for the simultaneous authentication of these herbal medicines in a single PCR reaction. Furthermore, we confirmed that commercial herbal medicines could be successfully used in the assay. Therefore, our method could be used to reliably detect adulteration and to standardize the quality of Adenophorae Radix.

\section{Materials and Methods}

\subsection{Plant and Herbal Materials}

Twenty-four plant samples were used: four samples each of A. stricta, A. triphylla, A. triphylla var. japonica, and G. littoralis, three samples of $C$. lanceolata, and five samples of $C$. pilosula (Table 1). Fresh leaves were collected from native habitats and plantations in different geographical locations in Korea and China, and stored at $-70{ }^{\circ} \mathrm{C}$ after freezing in liquid nitrogen. Herbal medicines were purchased from different herbal markets across Korea and China. All specimens of plants and herbal medicines were deposited in the Korean Herbarium of Standard Herbal Resources (IH code KIOM) after being given voucher numbers, as shown in Table 1 and Table 4. Morphological identification was performed using guidelines from the Classification and Identification Committee of the KIOM, which has nine experts in the fields of plant taxonomy, botany, pharmacognosy, and herbology.

Table 1. Plant materials used in this study.

\begin{tabular}{|c|c|c|c|c|c|}
\hline \multicolumn{2}{|l|}{ Name } & \multirow{2}{*}{ Habitat Information } & \multirow{2}{*}{ Voucher Number } & \multirow{2}{*}{ Abbreviation } & \multirow{2}{*}{$\begin{array}{l}\text { Lane } \\
\text { in Gel }\end{array}$} \\
\hline Scientific Name (Family) & Herbal Name & & & & \\
\hline \multirow{4}{*}{$\begin{array}{l}\text { Adenophora stricta Miq. } \\
\text { (Campanulaceae) }\end{array}$} & \multirow{4}{*}{$\begin{array}{l}\text { Adenophorae } \\
\text { Radix }\end{array}$} & Caoping, Li, Longnan, Gansu, China & KIOM200701000519 & AS-CP & 1 \\
\hline & & Jisan, Jindo, Jeonnam, Korea & KIOM200701000873 & AS-JS & 2 \\
\hline & & Guyuan, Ningxia, China & KIOM201201005303 & AS-GA & 3 \\
\hline & & Sangju, Gyeongbuk, Korea & KIOM201301006488 & AS-SJ & 4 \\
\hline \multirow{4}{*}{$\begin{array}{l}\text { Adenophora triphylla (Thunb.) A. } \\
\text { DC. (Campanulaceae) }\end{array}$} & \multirow{4}{*}{$\begin{array}{l}\text { Adenophorae } \\
\text { Radix }\end{array}$} & Cheoncheon, Jangsu, Jeonbuk, Korea & KIOM200701000682 & AT-CC & 5 \\
\hline & & Yaksan, Wando, Jeonnam, Korea & KIOM200701000741 & AT-YS & 6 \\
\hline & & Daegang, Danyang, Chungbuk, Korea & KIOM201101004148 & AT-DG & 7 \\
\hline & & Longjing, Yanbian, Jilin, China & KIOM201201005563 & AT-LJ & 8 \\
\hline \multirow{4}{*}{$\begin{array}{l}\text { Adenophora triphylla var. japonica } \\
\text { (Regel) Hara (Campanulaceae) }\end{array}$} & \multirow{4}{*}{$\begin{array}{l}\text { Adenophorae } \\
\text { Radix }\end{array}$} & Sancheong, Gyeongnam, Korea & KIOM201201004951 & ATJ-SC & 9 \\
\hline & & Beichuan, Mianyang, Sichuan, China & KIOM201201005359 & ATJ-BC & 10 \\
\hline & & Sangju, Gyeongbuk, Korea & KIOM201301006312 & ATJ-SJ & 11 \\
\hline & & Gandong, Hwacheon, Gangwon, Korea & KIOM201401009347 & ATJ-GD & 12 \\
\hline \multirow{3}{*}{$\begin{array}{c}\text { Codonopsis lanceolata } \\
\text { (Siebold \& Zucc.) Benth. \& Hook. } \\
\text { f. ex Trautv. (Campanulaceae) }\end{array}$} & \multirow{3}{*}{$\begin{array}{l}\text { Codonopsis } \\
\text { Lanceolatae } \\
\text { Radix }\end{array}$} & Sangju, Namhae, Gyeongnam, Korea & KIOM201001002725 & CL-SJ & 13 \\
\hline & & Sinan, Jeonnam, Korea & KIOM201101003615 & CL-SN & 14 \\
\hline & & Geochang, Gyeongnam, Korea & KIOM201201004752 & CL-GC & 15 \\
\hline \multirow{5}{*}{$\begin{array}{l}\text { Codonopsis pilosula (Franch.) } \\
\text { Nannf. (Campanulaceae) }\end{array}$} & \multirow{5}{*}{$\begin{array}{l}\text { Codonopsis } \\
\text { Pilosulae Radix }\end{array}$} & Ya'an, Sichuan, China & KIOM201101004238 & CP-YA & 16 \\
\hline & & Helong, Yanbian, Jilin, China & KIOM201101004335 & CP-HL & 17 \\
\hline & & Girin, Inje, Gangwon, Korea & KIOM200701000339 & CP-GR & 18 \\
\hline & & Jinbu, Pyeongchang, Gangwon, Korea & KIOM200801001104 & CP-JB & 19 \\
\hline & & Wangqing, Yanbian, Jilin, China & KIOM201101004270 & CP-WQ & 20 \\
\hline \multirow{4}{*}{$\begin{array}{l}\text { Glehnia littoralis F. Schmidt } \\
\text { ex Miq. (Apiaceae) }\end{array}$} & \multirow{4}{*}{ Glehniae Radix } & Gujwa, Jeju, Jeju, Korea & KIOM200601000041 & GL-JJ & 21 \\
\hline & & Anmyeon, Taean, Chungnam, Korea & KIOM200701000230 & GL-AM & 22 \\
\hline & & Geojin, Goseong, Gangwon, Korea & KIOM200701000231 & GL-GJ & 23 \\
\hline & & Jukbyeon, Uljin, Gyeongbuk, Korea & KIOM200601000062 & GL-JB & 24 \\
\hline
\end{tabular}




\subsection{Preparation of Genomic DNA and PCR Amplification}

Genomic DNA was extracted from the herbal medicines and the fresh leaves stored at $-70{ }^{\circ} \mathrm{C}$ using DNeasy Plant Mini Kits (Qiagen, Valencia, CA, USA). The DNA concentration and purity was determined using a Nanodrop ND-1000 (Nanodrop, Wilmington, DE, USA) and electrophoresis through $1.5 \%$ agarose gel with known standards. The final concentration of the DNA samples was adjusted to approximately $15 \mathrm{ng} / \mu \mathrm{L}$ with TE buffer and stored at $-20{ }^{\circ} \mathrm{C}$ pending PCR amplification.

The nrDNA-ITS regions were amplified using the primers ITS1 (5'-TCC GTA GGT GAA CCT GCG G-3') and ITS4 (5'-TCC TCC GCT TAT TGA TAT GC-3') with previously-reported PCR parameters [27,28]. PCR reactions were performed in $50 \mu \mathrm{L}$ mixtures consisting of $10 \mathrm{mM}$ Tris- $\mathrm{HCl}$ (pH 9.0), $2.5 \mathrm{mM} \mathrm{MgCl} 2,200 \mu \mathrm{M}$ of each dNTP, $10 \mathrm{mM}\left(\mathrm{NH}_{4}\right)_{2} \mathrm{SO}_{4}, 0.5 \mathrm{U}$ Taq DNA polymerase (SolGent, Daejeon, Korea), $0.5 \mu \mathrm{M}$ of each primer, and $15 \mathrm{ng}$ of template DNA. PCR amplification was carried out using a Proflex PCR system (Applied Biosystems, Foster City, CA, USA) with the following parameters: $95^{\circ} \mathrm{C}$ for $5 \mathrm{~min}$ (pre-denaturation); 35 cycles of $30 \mathrm{~s}$ at $95^{\circ} \mathrm{C}$ (denaturation), $30 \mathrm{~s}$ at $55^{\circ} \mathrm{C}$ (annealing), and $2 \mathrm{~min}$ at $72{ }^{\circ} \mathrm{C}$ (extension); and a final extension for $5 \mathrm{~min}$ at $72{ }^{\circ} \mathrm{C}$. PCR products were separated on $1.5 \%$ agarose gels with a 100 bp DNA ladder (SolGent, Daejeon, Korea).

\subsection{Analysis of Nucleotide Sequences and Phylogenetic Relationships}

The nrDNA-ITS amplicons (approximately $800 \mathrm{bp}$ long) were extracted from the agarose gels using a Gel Extraction Kit (SolGent, Daejeon, Korea) and subcloned into the pGEM-T Easy vector (Promega, Madison, WI, USA) for sequencing. The cloning of inserts was confirmed by colony PCR using the vector primer set, T7 and SP6, and the sequences of cloned amplicons were determined on both strands by Sanger sequencing using ITS1 and ITS4 primers and an automatic DNA sequence analyzer (ABI 3730, Applied Biosystems Inc., Foster City, CA, USA). To check the sequence quality of the amplified products for each sample, such as PCR errors, misreading, and geographical sequence variation, we obtained nucleotide sequences from five inserted DNA fragments per sample and compared their nucleotide sequences after alignment of the entire sequences using the multiple alignment tool (version 7.2.5, BioEdit, North Carolina State University, Raleigh, NC, USA) [29]. In addition, all sequences were subjected to a similarity search against the GenBank database to confirm the origins of the individual nrDNA-ITS sequences using a basic local alignment search tool (BLAST, http:/ / blast.ncbi.nlm.nih.gov/Blast). The resulting representative nrDNA-ITS sequences of each sample were registered in the NCBI GenBank (accession numbers: A. stricta, KY829514-KY829517; A. triphylla, KY829518-KY829521; A. triphylla var. japonica, KY829522-KY829525; C. lanceolata, KY829526-KY829528; C. pilosula, KY829529-KY829533; and G. littoralis, KY829534-KY829537).

The final sequences of the $\sim 800 \mathrm{bp}$ nrDNA-ITS amplicons were analyzed and manually curated using the BioEdit program, version 7.2.5 [29]. The inter- and intra-species variability of all sequences was analyzed using the MEGA6 program, version 6.06, with the Kimura-2-parameter (K2P) model [30]. To analyze the phylogenetic relationships of the species targeted in this study, we inferred a phylogenetic tree using the neighbor joining (NJ) method with the K2P model, pairwise deletion for gaps/missing data treatment, and 1000 replications for bootstrapping with Cisium japonicum (KM051436) as an outgroup reference.

\subsection{Development of the Multiplexed SCAR Marker Assay and Monitoring of Commercial Herbal Medicines}

Primers specific for the four herbal medicines were designed after aligning the 24 sequences with ClustalW in BioEdit [29]. Several candidate SCAR forward primers specific to the four herbal medicines were designed, along with one common reverse primer, based on the unique indels and/or base substitutions of the aligned ITS1 region sequences. For verifying primer specificity, PCR amplification was carried out in $20 \mu \mathrm{L}$ of reaction mix (a mix similar to the nrDNA-ITS reaction, but with $0.5 \mu \mathrm{M}$ of each SCAR primer instead of the ITS1 and ITS4 primers). PCR amplification conditions were as follows: $95^{\circ} \mathrm{C}$ for $5 \mathrm{~min}$; 35 cycles of $95^{\circ} \mathrm{C}$ for $1 \mathrm{~min}, 65^{\circ} \mathrm{C}$ for $30 \mathrm{~s}$, and $72{ }^{\circ} \mathrm{C}$ for $1 \mathrm{~min}$; and a final 
extension at $72{ }^{\circ} \mathrm{C}$ for $5 \mathrm{~min}$. The PCR products were visualized using a $1.5 \%$ agarose gel to check the size and number of DNA fragments. To confirm the primer specificities, the DNA fragments were extracted and those sequences were compared with the original nrDNA-ITS sequences.

For establishing a multiplex assay method, four forward SCAR primers and one reverse primer, which together amplify differently sized DNA fragments for each herbal medicine, were combined in a single PCR reaction, and optimal conditions were determined by altering PCR parameters such as annealing time and temperature, and the concentration of the template and primers. The amplified PCR products were analyzed using a 1.5\% agarose gel to check the number and size of amplicons. To validate the multiplex-PCR method and adulteration of Adenophorae Radix in the markets, 37 commercially-processed Adenophorae Radix samples and adulterants were purchased, and their botanical origin was verified. Approximately $15 \mathrm{ng}$ of total genomic DNA was used in $20 \mu \mathrm{L}$ multiplex-PCR assay mixtures consisting of $10 \mathrm{mM}$ Tris- $\mathrm{HCl}(\mathrm{pH} 9.0), 2.5 \mathrm{mM} \mathrm{MgCl}, 200 \mu \mathrm{M}$ of each dNTP, $10 \mathrm{mM}\left(\mathrm{NH}_{4}\right)_{2} \mathrm{SO}_{4}, 0.5 \mathrm{U}$ Taq DNA polymerase (SolGent, Daejeon, Korea), and $0.5 \mu \mathrm{M}$ of each primer. PCR amplification parameters were as follows: $95^{\circ} \mathrm{C}$ for $5 \mathrm{~min} ; 35$ cycles of $95^{\circ} \mathrm{C}$ for $30 \mathrm{~s}$, $65{ }^{\circ} \mathrm{C}$ for $30 \mathrm{~s}$, and $72{ }^{\circ} \mathrm{C}$ for $1 \mathrm{~min}$; and a final extension at $72{ }^{\circ} \mathrm{C}$ for $5 \mathrm{~min}$. The PCR products were visualized using $1.5 \%$ agarose gel electrophoresis to check the size and number of DNA fragments.

\section{Results}

\subsection{Analysis of $n r D N A-I T S$ Sequences}

To analyze the variable sequences of the medicinal plants used in Adenophorae Radix and the related adulterants, we first amplified the nrDNA-ITS regions of the 24 original plant samples listed in Table 1, successfully amplifying the $\sim 800$ bp fragments. The sequences of all the PCR amplicons were determined using both T7 and SP6 primers after cloning into the pGEM-T Easy Vector system, and they were registered in GenBank with the accession numbers indicated in Materials and Methods. The length of the entire nrDNA-ITS region was 793-795 in three Adenophora species, $743 \mathrm{bp}$ in C. lanceolata and C. pilosula, and $689 \mathrm{bp}$ in G. littoralis. They aligned to a length of $799 \mathrm{bp}$ (Table 2). The sequence variability and species-specific sequence variants of the two ITS regions were analyzed separately. The intra- and inter-species variability of the ITS1 region was $0.0000-0.0205 \% \pm 0.0104 \%$ and $0.2760 \% \pm 0.2279 \%$ to $0.5810 \% \pm 0.0122 \%$, respectively, and that of ITS2 was $0.0000-0.0198 \% \pm$ $0.0114 \%$ and $0.2657 \% \pm 0.2132 \%$ to $0.5717 \% \pm 0.0133 \%$, respectively (Table 2). A. stricta had the most diverged ITS1 and ITS2 sequences within the species (intra-specific), whereas G. littoralis had the most variability among the species (inter-specific) (Table 2). The intra- and inter-species variability was similar between the ITS1 and ITS2 regions, but the species-specific nucleotide substitutions, which are useful for SCAR primer design, were more numerous in ITS1, especially between C. lanceolata and C. pilosula (Figure S1 and data S1). Therefore, we used the ITS1 region for the further development of SCAR markers for Adenophorae Radix and its adulterants.

To analyze the phylogenetic relationships among the four herbal medicines and related plant species, we inferred a phylogenetic tree based on the NJ method using full-length nrDNA-ITS sequences. As a result, twenty-four samples were clustered into four groups with $100 \%$ bootstrap values consisting of monophyletic Adenophorae Radix, Cdonopsis Lanceolatae Radix, Codonopsis Pilosulae Radix, and Glehniae Radix groups (Figure S2). At the species levels, C. lanceolata was genetically closer to $C$. pilosula than to the other species and G. littoralis was most distant from the other species. Furthermore, Adenophora species, A. stricta, A. triphylla, and A.triphylla var. japonica, did not cluster depending on species (Figure S2). These phylogenetic results confirmed that the four herbal medicines can be distinguished using the sequence variability of nrDNA-ITS regions. 
Table 2. Summary of the characteristics of nrDNA-ITS barcode sequences.

\begin{tabular}{ccccccc}
\hline \multirow{2}{*}{ Species } & \multicolumn{2}{c}{ Sequence Length (bp) } & \multicolumn{2}{c}{ Intra-Species Variability (\%) } & \multicolumn{2}{c}{ Inter-Species Variability (\%) } \\
\cline { 2 - 7 } & Constant & Aligned & ITS1 & ITS2 & ITS1 & ITS2 \\
\hline A. stricta & $793-795$ & 799 & $0.0205 \pm 0.0104$ & $0.0198 \pm 0.0114$ & $0.2840 \pm 0.2322$ & $0.2657 \pm 0.2132$ \\
A. triphylla & $793-795$ & 799 & $0.0111 \pm 0.0062$ & $0.0198 \pm 0.0101$ & $0.2760 \pm 0.2279$ & $0.2661 \pm 0.2169$ \\
A. triphylla var. japonica & $793-795$ & 799 & $0.0092 \pm 0.0061$ & $0.0192 \pm 0.0094$ & $0.2778 \pm 0.2292$ & $0.2686 \pm 0.2184$ \\
C. lanceolata & 743 & 799 & $0.0000 \pm 0.0000$ & $0.0029 \pm 0.0025$ & $0.3566 \pm 0.1824$ & $0.3233 \pm 0.1893$ \\
C. pilosula & 743 & 799 & $0.0047 \pm 0.0061$ & $0.0035 \pm 0.0045$ & $0.3480 \pm 0.1560$ & $0.3375 \pm 0.1678$ \\
G. littoralis & 689 & 799 & $0.0023 \pm 0.0025$ & $0.0000 \pm 0.0000$ & $0.5810 \pm 0.0122$ & $0.5717 \pm 0.0133$ \\
\hline
\end{tabular}

\subsection{Development of SCAR Markers for Distinguishing Herbal Medicines}

To screen the candidate sequences for locations for species-specific SCAR primers, we analyzed the entire sequence and identified several variable regions for each herbal medicine (Figure S1). We designed several forward primers matching the diverged sequences in ITS1 and one common reverse primer (ITS1 SCAR R) to the conserved 5.8S gene (Figure 1). We verified the specificity of the PCR amplification with the 24 plant samples listed in Table 1. The four SCAR primers, when combined with ITS SCAR R, amplified products with the expected sizes only in their respective samples (Table 3, Figures 1 and 2). The Adenophorae Radix-specific forward primer, AD ITS1 SCAR $\mathrm{F}$, and the reverse primer, ITS1 SCAR R, produced a $231 \mathrm{bp}$ amplicon only with the 12 samples from the three Adenophora species, whereas no PCR products were observed with the other 12 Adenophorae Radix-related plant samples (Figure 2). Therefore, this primer set differentiates Adenophorae Radix from its related herbal medicines. The other three specific forward primers, CL ITS1 ACAR F for C. lanceolata, CP ITS1 SCAR F for C. pilosula, and GL ITS1 SCAR F for G. littoralis, also amplified their expected 267, 167, and 124 bp products only in their respective target species, with no products detected using the other samples (Table 3 and Figure 2). Thus, these three SCAR markers distinguish individual herbal medicines from Adenophorae Radix and identify plant material at the species level.

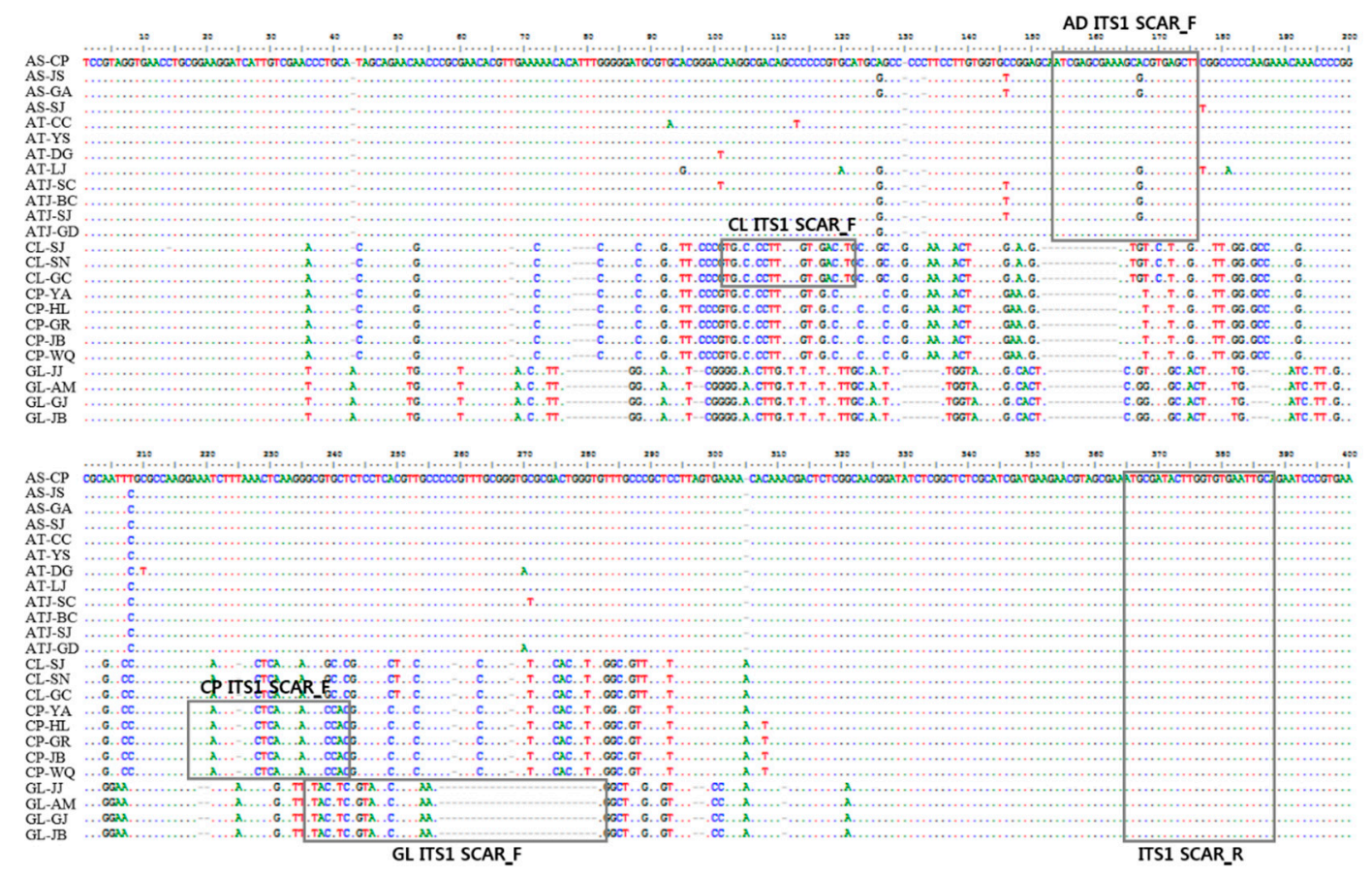

Figure 1. Comparative analysis of ITS1 region sequences and the positions of species-specific primers. Sequences were aligned using ClustalW in BioEdit (version 7.2.6). Boxes indicate the sequence of SCAR (sequence-characterized amplified region) primers used in the multiplex SCAR assay. Primer names are indicated under or above the boxes. 
Table 3. Sequences of the ITS1-SCAR primers and their specificity, amplicon sequence, and amplicon size.

\begin{tabular}{|c|c|c|c|c|}
\hline Primer Direction & Primer Name & Primer Sequence $\left(5^{\prime} \rightarrow 3^{\prime}\right)$ & Specificity & Amplicon Size (bp) \\
\hline \multirow{4}{*}{ Forward } & AD ITS1 SCAR F & ATC GAG CGA AAG CGC GTG AGC T & Adenophora sp. & 231 \\
\hline & CL ITS1 SCAR F & TGG CCC CTT GCC GTC GAC CT & C. lanceolata & 267 \\
\hline & CP ITS1 SCAR F & AAA ACT TAA CTC AAA GAG CGC GA & C. pilosula & 167 \\
\hline & GL ITS1 SCAR F & GTA CGT CCG TAT CCC GTT AAG G & G. littoralis & 124 \\
\hline Reverse & ITS1 SCAR R & GCA ATT CAC ACC AAG TAT CGC AT & All samples & - \\
\hline
\end{tabular}

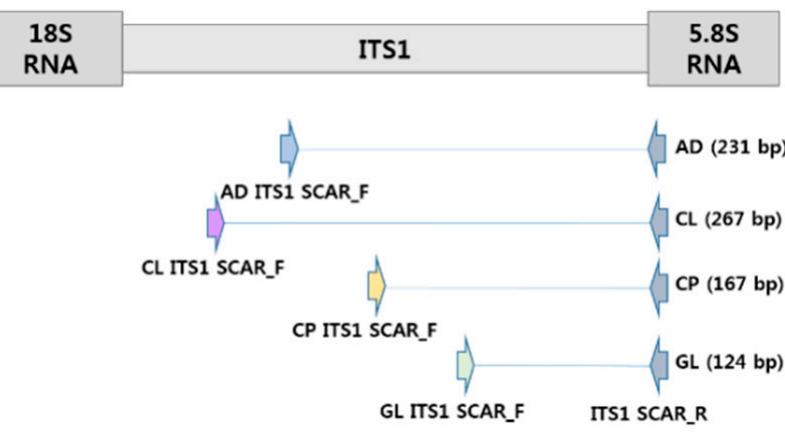

(a)

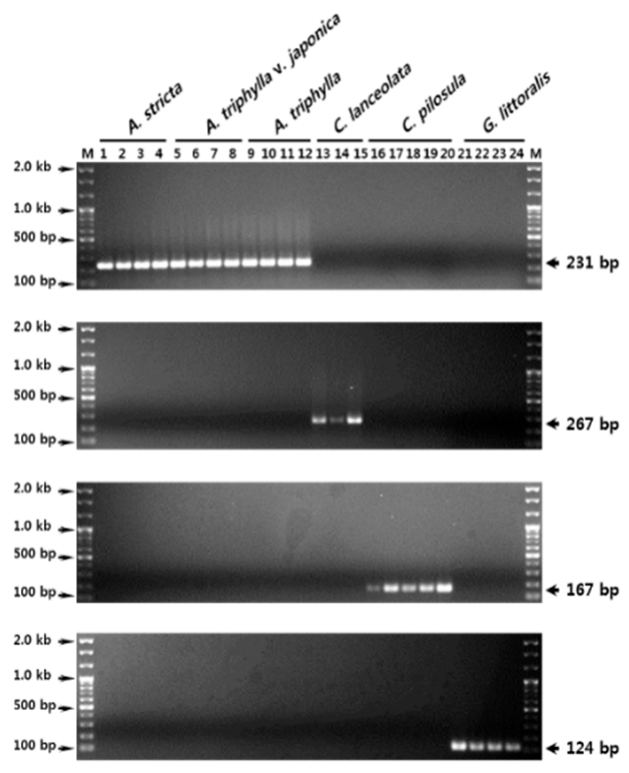

(b)

Figure 2. Development of species-specific SCAR markers based on inter-species sequence variability. (a) Schematic diagram of primer position and SCAR amplicon sizes; and (b) the verification of primer specificity for Adenophorae Radix, Codonopsis Lanceolatae Radix, Codonopsis Pilosulae Radix, and Glehniae Radix. The numbers 1-24 correspond to those listed in Table 1, in the 'Lane in gel' column. The precise lengths of DNA fragments are indicated to the right side of the gel images. M represents the 100 bp DNA ladder.

\subsection{Establishment of a Multiplex SCAR Amplification Method and Monitoring of Commercially-Processed} Herbal Medicines

The four individual SCAR markers produced mutually uniquely-sized amplicons that could be used to differentiate the four herbal medicines in a single gel electrophoresis. Therefore, we used a multiplex-PCR assay to concurrently amplify the SCAR amplicons. The combination of five primers, namely one common reverse primer (ITS1 SCAR R) and four forward primers (AD ITS1 SCAR F, CL ITS1 SCAR F, CP ITS1 SCAR F, and GL ITS1 SCAR F), was used in a single PCR reaction. We optimized the reaction conditions and PCR parameters, obtaining the same SCAR amplicons as those from the individual SCAR primer sets (Figure 3), suggesting that this multiplex-PCR assay can distinguish the four herbal medicines in a single reaction. 


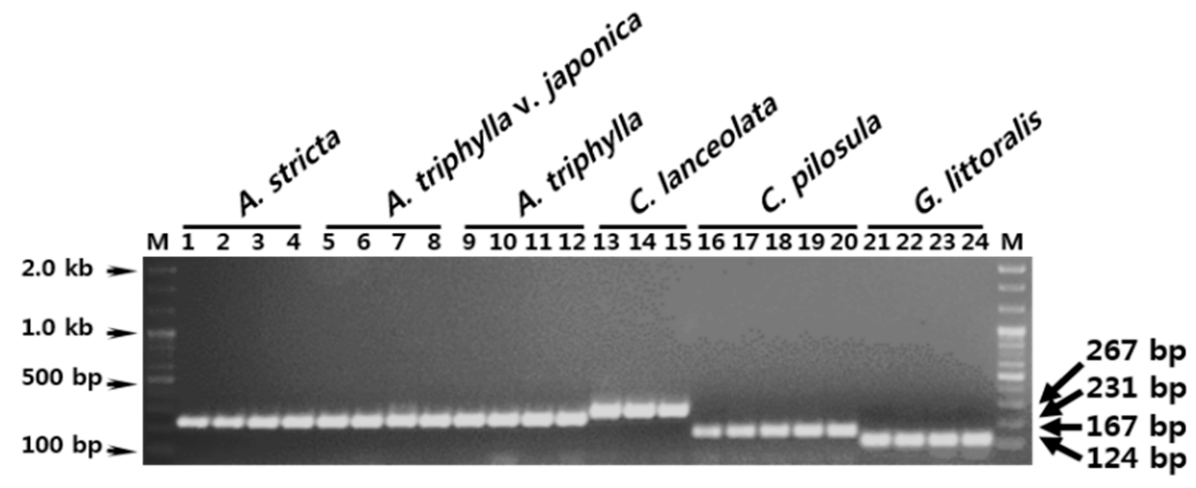

Figure 3. Establishment of a multiplex-PCR assay using species-specific SCAR markers. The numbers 1-24 correspond to those listed in Table 1. The precise lengths of DNA fragments are indicated to the right side of the gel images. $\mathrm{M}$ represents the $100 \mathrm{bp}$ DNA ladder.

To verify the reproducibility and investigate the present state of Adenophorae Radix distribution, we assessed 37 commercial herbal medicines using the multiplex SCAR assay (Figure 4 and Table 4). As shown in Table 4, we purchased 17, nine, eight, and three samples that were listed as Adenophorae Radix, Codonopsis Lanceolatae Radix, Glehniae Radix, and Codonopsis Pilosulae Radix, respectively. Of the 37 commercial herbal medicines, eight samples of Adenophorae Radix purchased in Korean herbal markets were identified as Codonopsis Lanceolatae Radix (the roots of C. lanceolata) (Figure 4 and Table 4). Thus, our multiplexed SCAR assay distinguished Adenophorae Radix from adulterants in commercially-processed herbal medicines in a single reaction. Our results indicate that our ITS1-based multiplexed SCAR marker assay could be used as a reliable genetic tool to protect against adulteration and to standardize the quality of Adenophorae Radix.

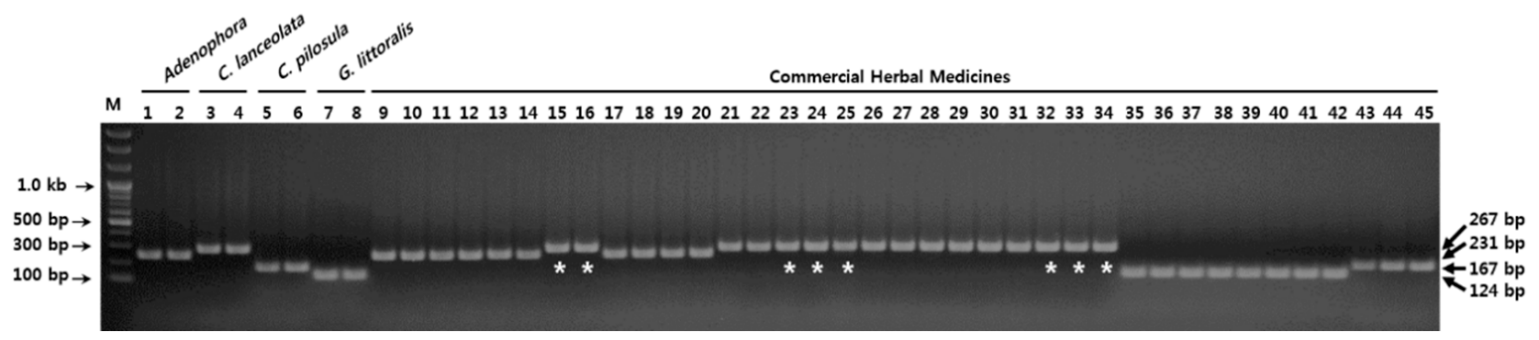

Figure 4. Monitoring of commercially processed herbal medicines using the multiplexed SCAR assay. Lanes 1-8: control plant materials used to develop SCAR markers. Lanes 9-45 correspond to the numbers 1-37 listed in Table 4, which are commercially-processed herbal medicines purchased from Chinese and Korean herbal markets. The precise lengths of DNA fragments are indicated to the right side of the gel images. M represents the $100 \mathrm{bp}$ DNA ladder. Asterisks $\left({ }^{*}\right)$ mark the inauthentic commercial herbal medicines. 
Table 4. Sample information and monitoring results of the 37 commercial herbal medicines assessed using our multiplexed SCAR assay.

\begin{tabular}{|c|c|c|c|c|}
\hline No. & Voucher No. & Product Name & Multiplex-SCAR Result & Country \\
\hline 1 & $2-15-0678$ & Adenophorae Radix & Adenophorae Radix & Korea \\
\hline 2 & $2-15-0679$ & Adenophorae Radix & Adenophorae Radix & Korea \\
\hline 3 & $2-15-0680$ & Adenophorae Radix & Adenophorae Radix & Korea \\
\hline 4 & $2-15-0681$ & Adenophorae Radix & Adenophorae Radix & Korea \\
\hline 5 & $2-15-0682$ & Adenophorae Radix & Adenophorae Radix & Korea \\
\hline 6 & $2-15-0683$ & Adenophorae Radix & Adenophorae Radix & Korea \\
\hline 7 & $2-15-0684$ & Adenophorae Radix & Codonopsis Lanceolatae Radix & Korea \\
\hline 8 & $2-15-0685$ & Adenophorae Radix & Codonopsis Lanceolatae Radix & Korea \\
\hline 9 & $2-15-0705$ & Adenophorae Radix & Adenophorae Radix & China \\
\hline 10 & $2-15-0706$ & Adenophorae Radix & Adenophorae Radix & China \\
\hline 11 & $2-15-0707$ & Adenophorae Radix & Adenophorae Radix & China \\
\hline 12 & $2-15-0708$ & Adenophorae Radix & Adenophorae Radix & China \\
\hline 13 & $2-15-0711$ & Codonopsis Lanceolatae Radix & Codonopsis Lanceolatae Radix & Korea \\
\hline 14 & $2-15-0712$ & Codonopsis Lanceolatae Radix & Codonopsis Lanceolatae Radix & Korea \\
\hline 15 & $2-15-0713$ & Adenophorae Radix & Codonopsis Lanceolatae Radix & Korea \\
\hline 16 & $2-15-0714$ & Adenophorae Radix & Codonopsis Lanceolatae Radix & Korea \\
\hline 17 & $2-15-0715$ & Adenophorae Radix & Codonopsis Lanceolatae Radix & Korea \\
\hline 18 & $2-15-0716$ & Codonopsis Lanceolatae Radix & Codonopsis Lanceolatae Radix & Korea \\
\hline 19 & $2-15-0717$ & Codonopsis Lanceolatae Radix & Codonopsis Lanceolatae Radix & Korea \\
\hline 20 & $2-15-0718$ & Codonopsis Lanceolatae Radix & Codonopsis Lanceolatae Radix & Korea \\
\hline 21 & $2-15-0719$ & Codonopsis Lanceolatae Radix & Codonopsis Lanceolatae Radix & Korea \\
\hline 22 & $2-15-0720$ & Codonopsis Lanceolatae Radix & Codonopsis Lanceolatae Radix & Korea \\
\hline 23 & $2-15-0721$ & Codonopsis Lanceolatae Radix & Codonopsis Lanceolatae Radix & Korea \\
\hline 24 & $2-15-0722$ & Adenophorae Radix & Codonopsis Lanceolatae Radix & Korea \\
\hline 25 & $2-15-0723$ & Adenophorae Radix & Codonopsis Lanceolatae Radix & Korea \\
\hline 26 & $2-16-0302$ & Adenophorae Radix & Codonopsis Lanceolatae Radix & Korea \\
\hline 27 & $2-15-0730$ & Glehniae Radix & Glehniae Radix & Korea \\
\hline 28 & $2-15-0731$ & Glehniae Radix & Glehniae Radix & Korea \\
\hline 29 & $2-15-0732$ & Glehniae Radix & Glehniae Radix & Korea \\
\hline 30 & $2-15-0733$ & Glehniae Radix & Glehniae Radix & Korea \\
\hline 31 & $2-15-0734$ & Glehniae Radix & Glehniae Radix & Korea \\
\hline 32 & $2-15-0735$ & Glehniae Radix & Glehniae Radix & Korea \\
\hline 33 & $2-15-0736$ & Glehniae Radix & Glehniae Radix & Korea \\
\hline 34 & $2-15-0737$ & Glehniae Radix & Glehniae Radix & Korea \\
\hline 35 & $2-17-0017$ & Codonopsis Pilosulae Radix & Codonopsis Pilosulae Radix & China \\
\hline 36 & $2-16-0025$ & Codonopsis Pilosulae Radix & Codonopsis Pilosulae Radix & China \\
\hline 37 & $2-15-0025$ & Codonopsis Pilosulae Radix & Codonopsis Pilosulae Radix & China \\
\hline
\end{tabular}

\section{Discussion}

Conventional identification of plants has usually relied on morphology. However, morphological features, such as the shapes of leaves, inflorescences, and flowers, are removed during commercial processing. Since accurate identification of herbal medicine based on morphological taxonomic keys is difficult, a DNA barcode system was established for accurate and reliable discrimination of plant species and botanical origins for herbal medicines [14,15,25,31]. Plant DNA barcoding led to remarkable improvements in the identification of the botanical origins of herbal materials and in the quality control of herbal medicines, but it still cannot be applied to many plant taxa because of failed PCR amplification, insufficient sequence variability between species, and incomplete sequence information $[1,16,19]$. To overcome these limits, the comparative analysis of genomic polymorphisms, using methods such as RAPD and AFLP, and the investigation of new DNA barcode regions using plastid genome sequencing have been conducted for a large number of medicinal plant species $[15,24,32]$. SCAR markers and multiplexed SCAR marker assays, developed using sequence information from genomic analyses, as well as from DNA barcodes, have become popular because the assays are simple to perform and have low analytical cost. To identify the botanical 
origins of herbal medicine based on the DNA barcoding method, many experimental procedures are needed, such as DNA extraction, PCR amplification, gel electrophoresis and rescue, sub-cloning into the pGEM-T Easy vector, E. coli transformation and incubation, plasmid DNA purification and restriction enzyme digestion (or colony PCR), sequencing of inserted amplicons, and sequence comparison or BLAST search. These experimental processes require approximately three or four days of work. However, the SCAR-based method does not require PCR product extraction from the agarose gel, sub-cloning into the vector and transformation, plasmid DNA purification, sequencing, or even sequence analysis. Thus, this method needs only DNA extraction, PCR amplification, gel electrophoresis, and species identification, and can identify the botanical origin of herbal medicines within a few hours. Moreover, the DNA barcoding method involves additional costs for sub-cloning, transformation into the competent cell, and sequencing, which are not necessary in the SCAR method [21]. Judging from our laboratory experience, these additional costs amount to at least $\$ 300-\$ 400$ USD for the analysis of 10 herbal medicine samples. Therefore, the SCAR method is much more convenient and less expensive for the authentication of herbal medicines and for the identification of the botanical origins of herbal medicines than the DNA barcoding method [22,24,26]. In spite of these disadvantages, DNA barcoding is mightily important for plant species identification with high resolution and for obtaining primary sequence information in species-specific marker development.

The roots of several Adenophora species and of other related medicinal plant species, including G. littoralis, C. lanceolata, and C. pilosula, have different chemical properties and biological activities $[3,4,11]$. However, the roots of these three species are consistently mislabeled in herbal markets and used for inappropriate clinical purposes in both Korea and China. Therefore, we analyzed the plant species that have been used as authentic herbal medicines and inauthentic adulterants of Adenophorae Radix in Korea and China. Of note, A. tetraphylla was defined as a synonym of A. triphylla in a recent reconsideration of the taxonomic system for Adenophora Fischer, although the original plant material for Adenophorae Radix was described as the roots of $A$. tetraphylla and A. stricta in Chinese pharmacopoeia [6,7]. Therefore, we considered A. tetraphylla as A. triphylla in our taxonomic identification (Table 1).

Since DNA is usually degraded in commercial herbal medicines, genetic analysis must be amenable to short DNA fragments [33]. We considered this point for developing SCAR markers and designed diverse SCAR primers that amplify variable ranges of DNA fragments. We designed SCAR markers in the ITS1 region based on aligned nrDNA-ITS sequences. Sequence substitutions and indels were more abundant in ITS1 than in ITS2 (Figure S1). In fact, differences between C. lanceolata and C. pilosula were rarely identified in the ITS2 region. The SCAR primers were, therefore, designed only for the ITS1 region and selected for different amplicon sizes depending on the herbal medicine, allowing for optical discriminability and stable amplificability by the multiplexed SCAR assay (Figure 1). To assess and increase the reproducibility of single and multiplexed SCAR markers, we optimized the PCR conditions by adjusting the annealing temperature, time, and concentration of primers and templates as described in Materials and Methods. Finally, we confirmed the discriminability and amplificability of our assay by assessing the adulteration of commercially-processed Adenophorae Radix, Codonopsis Lanceolatae Radix, Glehniae Radix, and Codonopsis Pilosulae Radix samples. We successfully assessed 37 commercially-processed herbal medicines and identified eight cases of adulteration (Figure 4 and Table 4). To confirm the botanical origin and sequence identity of the PCR amplicons obtained using the multiplexed SCAR assay, PCR products were sub-cloned into the pGEM-T Easy Vector and sequenced. The resulting sequences were aligned with the entire nrDNA-ITS sequences obtained from control plant materials listed in Table 1 and were confirmed against GenBank data using BLAST searches. All the sequences were identical to the corresponding sequences of control plants listed in Table 1. These results demonstrate that our multiplexed SCAR marker assay is a useful genetic tool for differentiating between Adenophorae Radix and its commercial adulterants.

In this study, we could not identify the species used in Adenophorae Radix because the genus Adenophora cannot be well resolved at the species-level using universal DNA barcodes (Figures S1 
and S2). In a previous study, we analyzed the nrDNA-ITS regions and the chloroplast mat $\mathrm{K}$ and $r b c \mathrm{~L}$ gene sequences using several Adenophora species, but could not identify useful species-specific variability [34]. In addition, another study using the ITS2 sequence was unable to discriminate between species of the genus Adenophora [3]. We also could not differentiate three Adenophora species using nrDNA-ITS sequences in this study. These results confirm the low level of ribosomal sequence variation among species of the genus Adenophora. Therefore, to verify the accurate botanical origins of the roots of Adenophora species, further studies are needed to develop genetic markers for use in genomic fingerprinting analyses, such as RAPD, and comparative analyses of organellar or whole genome sequences are needed to obtain intra-species sequence information.

Supplementary Materials: The following are available online at www.mdpi.com/2076-3417/7/7/660/s1: Figure S1, Comparative analysis of nrDNA-ITS sequences used in this study; Data S1: FASTA file of nucleotide sequences of nrDNA-ITS used in this study; Figure S2: Phylogenetic relationships of medicinal plant species based on the nrDNA-ITS sequences.

Acknowledgments: We thank the 'Classification and Identification Committee of the KIOM' for critical identification and the Korean Herbarium of Standard Herbal Resources (IH code KIOM) for providing plant materials. This work was supported by the grant 'Development of Foundational Techniques for the Domestic Production of Authentic Herbal Medicines based on the Establishment of Molecular Authentication System' (K16403 and K17403) and funded by the Ministry of Science, ICT, and Future Planning (MSIP) of Korea to the Korea Institute of Oriental Medicine.

Author Contributions: Byeong Cheol Moon designed and performed the experiments and wrote the manuscript; Wook Jin Kim, Kyeong Suk Han and Inkyu Park performed the experiments; and Sungyu Yang, Young Min Kang and Renzhe Piao collected and identified the plant samples.

Conflicts of Interest: The authors declare that there are no conflicts of interest.

\section{References}

1. Ali, M.A.; Gyulai, G.; Al-Hermaid, F. Plant DNA Barcoding and Phyogenetics; LAP LAMBERT Academic Publishing: Saarbrücken, Germany, 2015; pp. 109-130.

2. Mitra, S.; Kannan, R. A Note on Unintentional Adulterations in Ayurvedic Herbs. Ethnobot. Leafl. 2007, 2007, 3.

3. Zhu, X.; Zhang, Y.; Liu, X.; Hou, D.; Gao, T. Authentication of Commercial Processed Glehniae Radix (Beishashen) by DNA Barcodes. Chin. Med. 2015, 10, 35. [CrossRef] [PubMed]

4. Zhao, K.J.; Dong, T.T.X.; Cui, X.M.; Tu, P.F.; Tsim, K.W.K. Genetic Distinction of Radix Adenophorae from Its Adulterants by the DNA Sequence of 5S-rRNA Spacer Domains. Am. J. Chin. Med. 2003, 31, 919-926. [CrossRef] [PubMed]

5. Kim, W.I.; Zhao, B.T.; Lee, J.H.; Lee, D.U.; Kim, Y.S.; Min, B.S.; Son, J.K.; Woo, M.H. Quantitative and Classification Analyses of Lupenone and $\beta$-Sitosterol by GC-FID in Adenophora triphylla var. japonica Hara and Codonopsis lanceolata. Nat. Prod. Sci. 2014, 20, 243-250.

6. The Plant List. Available online: http://www.theplantlist.org/tpl1.1/search?q=adenophora (accessed on 10 April 2017).

7. Defining Dictionary for Medicinal Herbs. Available online: http://boncho.kiom.re.kr/herbarium/codex.php (accessed on 10 April 2017).

8. Lee, M.Y.; Mo, S.Y.; Kim, D.W.; Oh, S.E.; Ko, B.S. Discrimination and Genetic Relationship of Adenophora triphylla (Thunb) A. DC. var. japonica Hara and Codonopsis lanceolata Trauty Using RAPD Analysis. Korean J. Med. Crop. Sci. 2001, 9, 205-210.

9. Kim, J.Y.; Lee, Y.J. A Study on a Morphological Identification of Adenophora triphylla var. japonica, Codonopsis lanceolata, Adenophora remotiflora and Codonopsis pilosula. Korea J. Herbol. 2007, 22, 121-126.

10. Bensky, D.; Clavey, S.; Stoger, E.; Gamble, A. Chinese Herbal Medicine Materia Medica; Eastland Press: Seattle, WA, USA, 1993; pp. 714-717, 818-822.

11. Min, S.H.; Han, H.S.; Lee, Y.J. Study on the Anti-oxidative Effects of Adenophorae Radix, Codonopsis lanceolatae Radix and Glehniae Radix cum Rhizoma on Liver Cells Isolated from Oxidatively Stressed Rat. Korea J. Herbol. 2009, 24, 109-119. 
12. Austerlitz, F.; David, O.; Schaeffer, B.; Bleakley, K.; Olteanu, M.; Leblois, R.; Veuille, M.; Laredo, C. DNA Barcode Analysis: A Comparison of Phylogenetic and Statistical Classification Methods. BMC Bioinform. 2009, 10 (Suppl. 14), S10. [CrossRef] [PubMed]

13. Mishra, P.; Kumar, A.; Nagireddy, A.; Mani, D.N.; Shukla, A.K.; Tiwari, R.; Sundaresan, V. DNA Barcoding: An Efficient Tool to Overcome Authentication Challenges in the Herbal Market. Plant Biotechnol. J. 2016, 14, 8-21. [CrossRef] [PubMed]

14. Chen, S.; Pang, X.; Song, J.; Shi, L.; Yao, H.; Han, J.; Leon, C. A Renaissance in Herbal Medicine Identification: From Morphology to DNA. Biotechnol. Adv. 2014, 32, 1237-1244. [CrossRef] [PubMed]

15. Sucher, N.J.; Carles, M.C. Genome-based Approaches to the Authentication of Medicinal Plants. Planta Med. 2008, 74, 603-623. [CrossRef] [PubMed]

16. Hollingsworth, P.M.; Graham, S.W.; Little, D.P. Choosing and Using a Plant DNA Barcode. PLoS ONE 2011, 6, e19254. [CrossRef] [PubMed]

17. Moon, B.C.; Kim, W.J.; Ji, Y.; Lee, Y.M.; Kang, Y.M.; Choi, G. Molecular Identification of the Traditional Herbal Medicines, Arisaematis Rhizoma and Pinelliae Tuber, and Common Adulterants via Universal DNA Barcode Sequences. Genet. Mol. Res. 2016, 15. [CrossRef] [PubMed]

18. Group, C.P.W.; Hollingsworth, P.M.; Forrest, L.L.; Spouge, J.L.; Hajibabaei, M.; Ratnasingham, S.; van der Bank, M.; Chase, M.W.; Cowan, R.S.; Erickson, D.L. A DNA Barcode for Land Plants. Proc. Natl. Acad. Sci. USA 2009, 106, 12794-12797. [CrossRef] [PubMed]

19. Hollingsworth, P.M. Refining the DNA Barcode for Land Plants. Proc. Natl. Acad. Sci. USA 2011, 108, 19451-19452. [CrossRef] [PubMed]

20. Yao, H.; Song, J.; Liu, C.; Luo, K.; Han, J.; Li, Y.; Pang, X.; Xu, H.; Zhu, Y.; Xiao, P.; et al. Use of ITS2 Region as the Universal DNA Barcode for Plants and Animals. PLoS ONE 2010, 5, e13102. [CrossRef] [PubMed]

21. Lam, K.Y.; Chan, G.K.; Xin, G.Z.; Xu, H.; Ku, F.; Chen, J.P.; Yao, P.; Lin, H.Q.; Dong, T.T.; Tsim, K.W. Comparison of ITS Sequence Analysis and RAPD-Derived Molecular Markers. Molecules 2015, 20, 22454-22462. [CrossRef] [PubMed]

22. Kim, W.J.; Moon, B.C.; Yang, S.; Han, K.S.; Choi, G.; Lee, A.Y. Rapid Authentication of the Herbal Medicine Plant Species Aralia continentalis Kitag. and Angelica biserrata CQ Yuan and RH Shan Using ITS2 Sequences and Multiplex-SCAR Markers. Molecules 2016, 21, 270. [CrossRef] [PubMed]

23. Xin, G.Z.; Lam, Y.C.; Maiwulanjiang, M.; Chan, G.K.; Zhu, K.Y.; Tang, W.L.; Dong, T.T.X.; Shi, Z.Q.; Li, P.; Tsim, K.W. Authentication of Bulbus Fritillariae Cirrhosae by RAPD-derived DNA Markers. Molecules 2014, 19, 3450-3459. [CrossRef] [PubMed]

24. Bhagyawant, S.S. RAPD-SCAR Markers: An Interface Tool for Authentication of Traits. J. Biosci. Med. 2016, 4, 1-9. [CrossRef]

25. Lee, Y.M.; Ji, Y.; Kang, Y.M.; Kim, W.J.; Choi, G.; Moon, B.C. Molecular Authentication of Pinelliae Tuber and Its Common Adulterants Using RAPD-derived Multiplex Sequence Characterized Amplified Region (multiplex-SCAR) Markers. Int. J. Clin. Exp. Med. 2016, 9, 40-50.

26. Moon, B.C.; Lee, Y.M.; Kim, W.J.; Ji, Y.; Kang, Y.M.; Choi, G. Development of Molecular Markers for Authentication of the Medicinal Plant Species Patrinia by Random Smplified Polymorphic DNA (RAPD) Analysis and Multiplex-PCR. Hortic. Environ. Biotechnol. 2016, 57, 182-190. [CrossRef]

27. Kim, W.J.; Ji, Y.; Choi, G.; Kang, Y.M.; Yang, S.; Moon, B.C. Molecular Identification and Phylogenetic Analysis of Important Medicinal Plant Species in Genus Paeonia Based on rDNA-ITS, matK, and rbcL DNA Barcode Sequences. Genet. Mol. Res. 2016, 15. [CrossRef] [PubMed]

28. White, T.J.; Bruns, T.; Lee, S.; Taylor, J. PCR Protocols: A Guide to Methods and Applications; Academic Press: New York, NY, USA, 1990; pp. 315-322.

29. Hall, T.A. BioEdit: A User-friendly Biological Sequence Alignment Editor and Analysis Program for Windows 95/98/NT. Nucleic Acids Symp. Ser. 1999, 41, 95-98.

30. Tamura, K.; Stecher, G.; Peterson, D.; Filipski, A.; Kumar, S. MEGA6: Molecular Evolutionary Genetics Analysis Version 6.0. Mol. Biol. Evol. 2013, 30, 2725-2729. [CrossRef] [PubMed]

31. Ratnasingham, S.; Hebert, P.D. BOLD: The Barcode of Life Data. Mol. Ecol. Notes 2007, 7, 355-364. [CrossRef] [PubMed] 
32. Daniell, H.; Lin, C.S.; Yu, M.; Chang, W.J. Chloroplast Genomes: Diversity, Evolution, and Applications in Genetic Engineering. Genome Biol. 2016, 17, 134. [CrossRef] [PubMed]

33. Särkinen, T.; Staats, M.; Richardson, J.E.; Cowan, R.S.; Bakker, F.T. How to Open the Treasure Chest? Optimising DNA Extraction from Herbarium Dpecimens. PLoS ONE 2012, 7, e43808. [CrossRef] [PubMed]

34. Ji, Y.; Moon, B.C.; Lee, A.Y.; Chun, J.M.; Choo, B.K.; Kim, H.K. Molecular Phylogenetic Position of Adenophora racemosa, an Endemic Species in Korea. Korean J. Med. Crop. Sci. 2010, 18, 379-388. 